Macedonian Pharmaceutical Bulletin, 66 (Suppl 1) 199 - 200 (2020)

Online ISSN $1857-8969$

UDC: 615.15:614.253.8(497.11)

DOI: 10.33320/maced.pharm.bull.2020.66.03.099

Short communication

\title{
Safe and effective medicines for all - one day project in Serbian pharmacies
}

\author{
Tatjana Šipetić ${ }^{1}$, Ivana Tadić ${ }^{2}$, Dragana Rajković ${ }^{1,}$, Sandra Vezmar Kovačević ${ }^{2}$, \\ Milica Ćulafić ${ }^{2}$, Tatjana Milošević ${ }^{3}$, Jelena Stefanović Vojinović ${ }^{4}$, Suzana Marinković ${ }^{5}$, \\ Mika Simišićc \\ ${ }^{I}$ The Pharmaceutical Chamber of Serbia, Mutapova 25, 11000 Belgrade, Serbia \\ ${ }^{2}$ University of Belgrade - Faculty of Pharmacy, Vojvode Stepe 450, 11000 Belgrade, Serbia \\ ${ }^{3}$ Community Pharmacy Melem, Zanatlijska 32, 15000, Šabac, Serbia \\ ${ }^{4}$ Community Pharmacy Lilly, Pilota Mihajla Petrovica 6, 11000 Belgrade, Serbia \\ ${ }^{5}$ Community Pharmacy Zaječar, Nikole Pasica 11-13, 19000 Zaječar, Serbia \\ ${ }^{6}$ Community Pharmacy Subotica, Matije Gupca 26, 24000 Subotica, Serbia
}

\section{Introduction}

The traditional roles of pharmacists are dispensing of $\mathrm{Rx}$ medicines and other medicines groups, care of patients, monitoring of medicines utilization, preparations of medicines (small-scale manufacture of $\mathrm{Rx}$ medicines), provision of traditional and alternative medications, care of patients' minor ailments, disease prevention and health promotion and informing other health care professionals (WHO Consultative Group, 1988.). In the previous period, these roles experienced significant changes. Pharmacists became professionals who not only provide/dispense medications to patients but cooperate more with other health care professionals about patients' therapy. Cooperation with other professionals overcomes the basic role of pharmacists (informing of other health care professionals) and leads up to collaborative practice with the patient as the center of care (Kehrer et al., 2013). The new role of pharmacists in medication optimization contributes to reduction in health care costs and savings of the healthcare public funds (Dalton and Byrne, 2017). Implementations of many new services enable pharmacists to give more contribution to public health of communities such as vaccination, diabetes prevention and management, COPD management etc. (Blouin and Adams, 2017).

The International Pharmaceutical Federation (FIP) provides support to pharmacists globally. With the aim to enhance the position of the pharmacists within the society and inspire pharmacists to be more involved in improving health of communities, the FIP encourages pharmacists to organize activities during the World Pharmacist day. The theme of the FIP World Pharmacists Day in 2019 was "Safe and effective medicines for all". In line with the defined theme, Pharmaceutical Chamber of Serbia organized the one-day project in community pharmacies nationwide. The aim of this paper is to present all services that pharmacists provided during this project.

\section{Materials and methods}

All members of the Pharmaceutical Chamber were invited to voluntarily participate in the project. During the World Pharmacists day $\left(25^{\text {th }}\right.$ of September 2019.) pharmacists provided different

\footnotetext{
*ivana.tadic@ pharmacy.bg.ac.rs
} 
services to patients' and all of these services were documented using the specially designed form. The form was designed by the Pharmaceutical Chamber expert group and first was tested on small sample of pharmacists.

\section{Results and discussion}

The results include data form 93 pharmacists who completely filled the form. They provided services to 536 patients. The average number of patients per pharmacist was 5.76 and 6.62 per community pharmacy. Patients who received the pharmacists' services were $64.99 \pm 12.81$ years old and mostly female $(57.28 \%)$. The average number of medicines per patient was $4.55 \pm 2.19$ and mostly belonged to $\mathrm{C}$ category using the ATC classification.

During the project pharmacists documented all medications, dietary supplements (DS) and other pharmacy products that patients used or were being prescribed to patients. The most of medications that patients used were being prescribed to patients by medical doctors (MD) $(91.37 \%$, mostly $\mathrm{Rx}$ medicines), recommended by pharmacists $(1.44 \%$, mostly OTC medicines) or used for self-medication (1.64\%, mostly OTC medicines). Dietary supplements were used by $59.33 \%$ patients and in average 1.66 DS per patient. DS were predominantly recommended by pharmacists $(52.80 \%)$, or were used by the opinion of patients themselves (28.24\%), or recommended by MD (18.95\%).

The most of pharmacists checked if the medicines regimen was appropriate $(94.78 \%$ ) and if the medicines usage is correct $(89.07 \%)$. During the medication review of patients' therapy pharmacists documented clinically important drug-drug interactions in $18.19 \%$ patients. They also notified adverse drug reactions in $2.54 \%$ of patients.
Other pharmacists-led interventions that were provided to patients were: Nonpharmacological interventions (education about lifestyle, such as advice to patients on healthy lifestyle, including diet, weight management, alcohol consumption and smoking cessation), counseling on regular measurements of clinical parameters, demonstration of correct use of medical devices, provision of advices about correct medicines storage and proper medicines' application $(82.09 \%, 72.20 \%, 17.91 \%$, $48.13 \%$ and $37.13 \%$ prospectively).

\section{Conclusion}

The study results indicated that pharmacists are highly motivated to provide specific interventions to patients. During the World Pharmacists day pharmacists have devoted more time to each patient and invested effort to help patients. These pharmacists-led interventions contributed to encouragement of pharmacists to improve health of patients, as well as to strengthening of the pharmacy profession.

\section{References}

Blouin, R.A., Adams M.L., 2017. The role of the pharmacist in health care: Expanding and evolving. NC. Med. J. 78(3), 165-167.

Dalton, K., Byrne, S., 2017. Role of the pharmacist in reducing healthcare costs: current insights. Integr. Pharm. Res. Pract. 6, 37-46.

Kehrer, J.P., Eberhart, G., Wing, M., Horon, K., 2013. Pharmacy's role in a modern health continuum. Can. Pharm. J. (Ott). 146(6), 321-324.

WHO Consultative Group., 1988. The Role of the Pharmacist in the Health Care System. 